\title{
Rearing Styles, Parents' Attachment Mental State, and Children's Social Abilities: The Link to Peer Acceptance
}

\author{
Grazia Attili, ${ }^{1}$ Patrizia Vermigli, ${ }^{2}$ and Antonio Roazzi $^{3}$ \\ ${ }^{1}$ Department of Social Sciences, University of Rome "Sapienza", Corso Italia, 00198 Rome, Italy \\ ${ }^{2}$ Institute of Cognitive Sciences and Technologies, CNR, 00185 Rome, Italy \\ ${ }^{3}$ Department of Psychology, Federal University of Pernambuco, 50670-901 Recife, CEP, Brazil
}

Correspondence should be addressed to Grazia Attili, grazia.attili@uniroma1.it

Received 4 November 2010; Accepted 23 March 2011

Academic Editor: Masha Gartstein

Copyright (C) 2011 Grazia Attili et al. This is an open access article distributed under the Creative Commons Attribution License, which permits unrestricted use, distribution, and reproduction in any medium, provided the original work is properly cited.

\begin{abstract}
This paper examines the discriminant effect of mothers' and fathers' attachment working models, the quality of their relationships in everyday settings, and children's social abilities on children's peer acceptance. Participants were thirty-four 7-9 year olds, their mothers, and fathers. Interactions were observed at home and coded on global measures of positive, negative, controlling, disconfirming, correcting behaviors, and neutral conversation. Parents' IWM were assessed by the AAI. Children's peer acceptance and behavioral orientations as a measure of a child's social competence at school were assessed by sociometric techniques. By using both traditional statistical analyses and a multidimensional scaling approach (MDS), in terms of "similarity structure analysis (SSA)" and the "external variables as points technique," it emerged that children's lack of success among peers associated with social behaviors which were linked to parents' rejecting/neglecting and directive interactive styles, mainly to negative, disconfirming, and a few positive interactions. These parenting styles were significantly affected by adults' insecure IWM.
\end{abstract}

\section{Introduction}

According to Bowlby $[1,2]$, parents provide children with demonstrations and working models of how to organize their relationships with others. Secure attachment relationships give them both the assurance that they are worthy of being loved and the expectation that others are keen to help when needed, so that they become self-confident and more competent within peer relationships across their lifespan. Recent research gives solid support for the theoretical proposition that a secure parent-infant attachment is associated with positive child outcome, and may serve as a protective factor against the development of negative and aggressive behaviors not only in infancy and early childhood (among others, [3$6]$; see $[7-9]$ and $[10,11])$ but also in middle childhood [12$16]$ and adolescence [17-20].

Indeed, in the above-cited studies, rather than the associations between assessments of the quality of parent-child bonds and behavior in peer groups, the relation between children's social competence and their own attachment working models was investigated on the assumption that these were the outcome of attachment relationships with parents. By contrast, it is of particular importance in assessing risk of maladaptive outcomes to have a direct measure of the quality of relationships children form with their primary caregivers (see, among others, [21]). Furthermore, it is important to investigate the extent to which parenting styles are influenced by mothers' and fathers' experiences in their own family of origin [22]. Studies in attachment research, in fact, have shown that children's relationships with their parents are linked to the adults' internal working models, which are the result of their history with attachment figures $([23,24]$; only as far as mothers are concerned [25-28]). And since many studies starting from the pioneering one by Main and Goldwin [29] have provided evidence of the associations between adults' attachment classifications and their children's attachment organizations [30, 31], it seems plausible to argue in favour of the hypothesis that the quality of a parent-child relationship might be considered one of the mechanisms for transferring security from parents to 
children so as to enhance social skills and adaptation within peer groups. Indeed, social competence might be considered a product of a child's working model $[1,32]$.

In the above-cited works on the associations between parents' IWM and the quality of their relationships with children, parenting style was assessed in laboratory settings, and the focus of the investigation was essentially the link between a parent's state of mind and either/both parental warmth and responsiveness or/and parents' ability to set appropriate limits for the child or to structure a teaching session. For example, in the study by Cohn et al. [23] on 27 children, their mothers, and their fathers, it was found that secure parents were more helpful, warm, and supportive in a series of teaching tasks, and more able to set appropriate limits for the child than were parents classified as insecure. Cowan et al. [24] found that, in four assigned tasks, insecure mothers were displaying a lower level of authoritative parenting, a variable including dimensions such as warmth/responsiveness, structure/limit setting, support for appropriate levels of autonomy; fathers' insecure adult attachment was not directly connected with parenting style; nevertheless, insecure fathers were less likely to be involved in coparenting their child when this one was in front of difficult tasks. Adam et al. [25] observed in their laboratory motherchild interactions in a series of tasks designed to be somehow frustrating for the children and found insecure preoccupied mothers to display angry/intrusive parenting and insecure dismissing ones to be low in positive affectivity. Little is known about the extent to which parents' attachment state of mind is related to other aspects of their relationships with children. Neglected in particular so far is the consideration of the link between parents' IWM and the nature of parentchild relations observed at home, in the everyday life settings. In addition, to our knowledge, in no study has consideration been given to the effect of this link on children's social competence and on social status in group settings assigned by same age companions. In fact in Cowan et al.'s study [24], for example, associations between parents' IWM, their rearing styles and children's adaptation to school were considering, for the last variable, dimensions such as school achievement and internalizing and externalizing behaviors assessed by means of a check list filled out by teachers rather than by peers. Furthermore, only a few studies addressed the associations between a child's adaptation and father-child bonds, and when they did the results were inconclusive $[17,24,33,34]$. For example, in Engels and colleagues'study [17] neither differences between perceived attachment to fathers and that one to mothers nor a specific link between an adolescent's adaptation and father-child bonds have been evidenced; by contrast Youngblade and colleagues [34] found an association between attachment security and friendship quality in 5 year olds only for the child-father relationship; Cowan et al. [24] found that first grade children's adaptation at school was associated with mothers' parenting while fathers' relational styles did not show a direct connection with children's outcomes.

Thus, moving from the above-cited studies and from research arguing and demonstrating how subsequent parents' sensitivity have a great role as well, respect to early attachments, in children's adjustment [5, 35-38], our research project took into consideration the role of the concurrent rearing environment-in terms of both mothers' and fathers' rearing styles and attachment mental states-on school-aged children's adaptation in peer groups.

The idea behind the above-cited studies is that social competence originates in child-parent relationships. Indeed, it has been queried that attachment acts causally [39]. Peer skills may develop within relationships with peers (for a review see [40]). At mean time, it has been suggested that maintaining the notion of the causal role in development of the internal mental representations of self and of others is useful even though there is a "need of empirical evaluation" [41, page 383]. In fact, to our knowledge, no research has taken into consideration the relative contribution of rearing styles, parents' attachment mental states, and children's social abilities to their success among peers. Thus the aim of our study was to examine the impact of both children's (social behaviors) and parental factors (parenting and parents's IWM) simultaneously as far as peer acceptance is concerned.

We took in consideration three behavioral dimensions which are mostly considered indicators of children's social competence: prosocial behavior, isolation, and aggressive behavior (see, among others, [42-45]). The conceptual assumption is that peer relations are important in fostering social competence in terms of getting along well with others, resolving conflicts, entering play, and promote effective adaptation in the environment (literature starting from [46]; for a discussion on the social competence construct see $[40,47-49]$ ). Behavior such as being prosocial (helping peers and sharing things with them) facilitates smooth interactions with peers. By contrast, aggressive behavior disrupts relations within peer groups. Social withdrawal also, even though in a less disruptive way, may associate to poor interactions and to missing opportunities for learning a variety of social skills. Children who are prosocial, not aggressive, and not withdrawing have more opportunities for being involved in peer interactions; for this reason they can be considered both the most socially competent ones and those whose basic competence can dialectically improve more easily. In fact, in past research these dimensions have been proved to link to peer acceptance, a factor which might be considered the outcome of social competence and a strong indicator of effective adaptation in the social environment ([49-54]; see also overviews by $[40,48,55])$. Nevertheless, children's aggression, prosociality, and social withdrawal might well be the outcome of parenting styles experienced at home (among others, $[3-5,12,13,24,56])$.

1.1. Aims of the Study. The present study is an improvement over previous ones in so far as it examines the different role of mothers' and fathers' attachment internal working models for what it is concerning the quality of their observed relationships with children in everyday settings, and the discriminant effect of these factors and children's social skills as far as their success among peers at school is concerned. In detail, we studied (1) the associations 
between parents' interactive styles and attachment mental states, (2) the differences between children's behaviors at school as a function of parents' attachment classifications, (3) the link between parents' attachment classifications and children's social status, (4) the relations between parental interactive styles, children's behavioral orientations at school, and peer acceptance, and (5) the different role of parental interactive styles, their attachment status, and children's behavioral orientations at school as far as children's popularity is concerned, rejection, and being average in the peer group.

As a further point, (6) we were also wondering about the internal structure underlying the quality of a child's relationship with his/her mother and father. Our hypothesis was that this structure relates both to parents' attachment mental states and peer social status. In other words we did not limit our investigation to assess the associations between parents' IWM, parental behavioral categories, children's social abilities, and peer acceptance. By internal structure, in fact, we mean the map that emerges by the simultaneous intercorrelations of each parental behavioral category with all the others [57]. Indeed, to our knowledge, this is the first study that has attempted to establish this structure, to show its relation with the above-mentioned external variables, and to give evidence to the extent to which children's adaptation is the result of a very complex family context. For this analysis we relied on a multidimensional scaling approach (MDS) using "similarity structure analysis (SSA)" and the "external variables as points technique" developed by Cohen and Amar [58-60]. The consideration of this link may provide support for possible future interventions in education and in the clinical area.

\section{Method}

2.1. Participants. Participants were 34 school-age children (14 boys and 20 girls), their mothers and fathers living in Rome, Italy, and primarily of middle class background. Children's age ranged from 7 years and 6 months to 9 years and 3 months (mean age $=8$ years and 2 months; $\mathrm{SD}=.74$ ). Fathers' average age was 40 years (range $=34-44$ years; $\mathrm{SD}=3.82$ ) and mothers' was 34 (range $=28-40$ years; $\mathrm{SD}=$ 2.43). All fathers had an average of 13 years formal education, $60 \%$ had a university degree. Mothers had at least 10 years of schooling, $40 \%$ had a university degree. All the fathers were employed full time, while $50 \%$ of mothers were employed full time $30 \%$ part time, and $20 \%$ were not working outside of the home.

The sample was recruited through contacts with teachers of schools attended by the children. We asked teachers the permission of interviewing children and to be introduced to their families. Families were contacted, and we explained to fathers and mothers the aim of the study asking for their collaboration. The children in our sample were attending 16 different third and fourth grades of 4 primary schools and so the measurement of their social status and behavioural orientations is based on peer nominations of 224 subjects (116 boys and 108 girls).

\subsection{Procedures and Instruments}

2.2.1. Assessment of Adult Attachment. Mothers and fathers were interviewed in their homes individually and separately by one of five trained experimenters. Each parent was administered the adult attachment interview (AAI) [61], a semistructured interview for adults focused on childhood attachment experiences and the meaning currently assigned by an individual to past attachment-related experiences.

The AAI includes questions about experiences within the family relevant for the making of attachment bonds. Subjects are asked to try to remember childhood relationships with parents, experiences of being upset, or ill, feelings of rejection, memories of separation, and loss. Furthermore, they are asked why they feel their parents had behaved as they did and how their present relationship with their parents is.

Each interview lasted approximately one hour and was audio-taped. Interviews were then coded from the written transcripts by the first author who had received extensive training in the scoring procedures for the AAI in two training institutes run by Mary Main, with whom she obtained an interrater reliability of $85 \%$. In order to avoid the members of a couple being identified, mothers' and fathers' transcripts were assigned different identification numbers and were scored separately.

As it is well known, the scoring procedures include ratings on two sets of 9-point scales. The first one includes ratings of parental behavior displayed towards the subjects in their childhood; the second scale assesses the state of mind, that is, it includes ratings of the coherence of current thinking about attachment relationships $[29,62]$. Patterns of scale scores were used to assign an adult to one of three major classifications: a secure category, "autonomous", or one of two insecure categories, "dismissing" or "preoccupied", with the coherence scales being used to make secure-insecure distinctions.

2.2.2. Parent-Child Relationships: Direct Observation. The quality of mother-child and father-child relationships was assessed by means of direct observation carried out in the subjects' homes. We observed each child interacting separately with his/her mother and his/her father in a random order. Each dyad (34 mother-child and 34 fatherchild dyads) was videotaped twice during 10-minute freeplay sessions within an unstructured situation over a 2week period by five trained female observers. Experimenters supplied on both days a collection of toys both sex typified and undifferentiated for boys and girls (such as dolls to be dressed with several kinds of cloths, small motor racing cars, puzzles, papers and coloured pencil, learning toys, etc.) that could facilitate parent-child interactions. In order to characterize the setting as "everyday life," parents were asked to do whatever they liked or were accustomed to doing with the child when he/she was receiving new toys. This means that parents were free not to play with toys in case this was not part of their daily routine. Parents might have been interacting just verbally. Indeed, our goal was to assess relational styles rather than types of play children were involved in with their parents. 
Drawing from previous research involving direct observation of parenting styles and children's competence (e.g., [63-65]) and since our aim was to have a measure of children's concurrent rearing environment within their everyday life, interactions were coded using a modified version of Hinde's [66] ethological coding scheme. This manual allows the different aspects of interactive styles that can be picked up by direct observation "in the field" to be measured. Furthermore, interactions can be coded within categories that let parents' responsiveness, rejection, neglecting, and directiveness to be measured, in line with the concept of parenting style by Baumrind $[67,68]$ and with the focus of our interest within the attachment theory.

Fathers' and mothers' behavior towards their children was coded by separate raters into one of 50 interactive categories in terms of one-zero frequency during 10-second intervals. A maximum of 60 intervals for each mother and 60 for each father was coded. The categories were then grouped into six broader ones in accordance with Hinde's cluster analysis-based conceptualisation [69].

Each parent-child interaction's rater was blind to parents' attachment classification, to the observation of the other parent with the child, and to his/her sociometric status. Agreement between observers and the reliability for the observed interactions was calculated, using $15 \%$ of both mother-child and father-child videos, in terms of the ratio between agreements and the sum of agreements and disagreements. Interobserver reliabilities (Cohen's Kappa) ranged from 0.74 to 0.87 ( mean score $=0.81$ ).

The six broad categories and some of their operational definitions were as follows (Cohen's Kappa for each category is given in parentheses): (a) neutral conversation (0.75) talking about neutral themes and giving information; (b) positive behavior (0.87) - physically friendly (maintaining contact, hugging, and kissing), approving, encouraging, helping, comforting, protecting, and sharing; (c) negative behavior (0.85) - threatening, criticizing, interfering, asserting self, and hostility expressed in several ways; (d) control patterns (0.84)-inhibiting, forbidding, commanding, and suggesting; (e) correcting (0.76) - giving new information and correcting; (f) disconfirming (0.74)-ignoring and answering irrelevantly. The absolute frequency of behaviors recorded for each interactant (mother towards his/her child; father towards his/her child) in each category within the total time of observation was calculated.

2.2.3. Sociometric Assessment and Peer Acceptance. Children's social status was assessed by the same five experimenters who visited the families at home. Assessment work was distributed in order to ensure experimenters were blind to the coding of parent-child interaction.

As mentioned previously, our subjects were found to attend 16 different classes. For this reason 224 children (116 boys and 108 girls) were asked to name which three of their classmates they liked most and least to play with. Same-gender "play with" nominations were used. Separate positive and negative scores were created by summing the nominations children got for each question. $Z$ scores were then calculated by class. By subtracting each standardized negative nomination score from its positive counterpart a measure of social preference (SP) was created. By summing negative and positive standardized scores a social impact measure (SI) was obtained. SP and SI scores plus the positive and negative standardized scores were used to assign children to social status categories according to formulae developed by Coie et al. [70].

\subsubsection{Peer Nominations for Aggression, Social Isolation, and} Prosocial Behaviour. A peer nomination measure based on the one developed by Coie and Dodge [71] was used. The aggression item was "who mostly starts fights and/or insults others?" The question "who always stays alone and withdraws from others?" was added as a parallel question for isolation. In order to measure prosocial behaviour, a final question was added: "who mostly helps others and shares his/her things?" $Z$ scores based on same-gender nominations were calculated as well for these behavioral nominations in the whole sample of 224 youngsters. In a previous study we found substantial correlations between peer and teacher nomination of aggression $(r=.56)$, withdrawal $(r=.45)$, and prosocial behaviour $(r=.62)$ [50]. These correlations are in line with those found in North American research on aggression and social withdrawal [72].

2.3. Analysis Strategies. In order to study (1) associations between parents' interactive styles and attachment mental states, (2) differences between children's behaviors at school as a function of parents' attachment classifications, (3) the link between parents' attachment classifications and children's social status, (4) relations between parental interactive styles, children's behavioral orientations at school, and peer acceptance, and (5) the different role of parental interactive styles, their attachment status, and children's behavioral orientations at school as far as concern children's popularity and rejection in the peer group, given the small sample size we used traditional nonparametric statistical tools such as Mann-Whitney tests for (1) and (2), correlational analyses for (3) and (4), and regressions for (5) having parenting styles such as numeric variables, parents' attachment IWM, children's behaviors and social status such as dchotomic ones. As far as the relation between parental interactive styles, their attachment working models, and children's peer status is concerned (6) we relied on a multidimensional scaling approach (MDS) using "similarity structure analysis (SSA)" and the "external variables as points technique" developed by Cohen and Amar [58-60]. In fact, investigating this association implies establishing not only the terms in which IWM and children's peer acceptance relate to differences in parents' behavioral categories but also describing the global structure of the latter and relating this structure to the other two groups of variables.

\section{Results}

Neither mothers' nor fathers' classifications on the AAI were associated with any variables such as child's gender, parents' 
age and education, and duration of the couple's relationship. In order to verify whether the associations between the quality of a parent-child relationship and parents' IWM were influenced by the child's gender, we initially conducted all the analyses separately for boys and girls. In fact we were wondering whether secure parents might be using equally positive behaviors to both boys and girls while insecure ones' rearing styles might be affected by children's sex. No significant differences emerged; thus, we analysed all the data for the entire sample.

3.1. Descriptive Data: Mothers' and Fathers' Attachment Typologies. As far as the distribution of mothers and fathers along attachment typologies is concerned we found that as far as mothers were concerned $18(53 \%)$ were secure, 12 (35\%) dismissing, and $4(12 \%)$ preoccupied; as far as fathers were concerned we found $16(47 \%)$ secure ones, 12 (35\%) dismissing, and $6(18 \%)$ preoccupied.

Just five adults (three mothers $(9 \%)$ and two fathers $(6 \%)$ ) had experienced a major loss and were found to be "unresolved." Nevertheless, since their basic classification was preoccupied, in view of the small numbers involved, they were not considered as belonging to a separate category. Given the small sample size, we collapsed the dismissing and preoccupied interviews into one insecure group to be contrasted with the secure group.

Strong associations were found between the AAI classifications of wives and husbands: $76 \%$ of the secure mothers had a secure partner. $81 \%$ of insecure mothers had an insecure partner $(\mathrm{phi}=.577$, df $1, P<.001)$.

3.2. Descriptive Data: Children's Social Status at School. As far as children's social status at school of the 34 children in the observed sample is concerned, 15 participants were found to belong to the popular group, that is, they were among those who were chosen as mostly liked children and less nominated among those peers liked least; 8 to the rejected one, that is, they had been nominated mostly among those peers liked least and less among those peers liked most, and 11 to the average one, that is, as far as peer nominations are concerned, these children were in between the other two groups. By chance, no child was found to be controversial and neglected.

3.3. Parents' Interactive Styles and Attachment Working Models. As mentinned above, given the small sample size, the association between the adults' attachment classifications and the mean frequency of observed parenting behaviors per time of observation was examined using separate MannWhitney tests for each parent.

The findings suggest that adult attachment classifications were related to parenting behavior for both parents. As shown in Table 1, secure mothers, compared to the insecure ones, displayed more positive $(U=57.50, P<.003)$ and less negative behavior $(U=84.00, P<.031)$, less control patterns $(U=82.50, P<.030)$, and less disconfirming ones $(U=96.00, P<.039)$.

Secure fathers also displayed more positive $(U=21.53$, $P<.009)$, less negative behavior $(U=80.50, P<.020)$, and less disconfirming patterns than insecure ones $(U=81.00$, $P<.028)$.

\subsection{Children's Behavioral Orientation at School and Socio-} metric Status as a Function of Parents' Attachment Working Models. A Mann-Whitney test was computed as well to analyze the differences between children's behaviors at school as a function of parents' attachment classifications. Secure mothers had children who tended to be less aggressive and isolate and were more prosocial towards peers than those of insecure mothers (statistical significance was reached only for the last variable $(U=85.0 ; P<.05)$. The same trend was found for fathers (significance was reached only for isolation $(U=76.0 ; P<.05$; Table 2).

As far as the link between parents' attachment classifications and children's social status was concerned, we found that while popular and average children had a high percentage of secure mothers $(73 \%$ and $60 \%$, resp.) and fathers ( $70 \%$ and $53 \%$, resp.), rejected ones had quite a high percentage of insecure parents ( $88 \%$ for both parents; phi correlation coefficients for mothers: $.12 \mathrm{~ns} ; .27 P<.05 ;-.45$ $P<.01$, resp, for fathers: $.09 \mathrm{~ns} ; .29 P<.05 ;-.41 P<.01)$.

\subsection{Parental Interactive Styles, Children's Behavioral Orienta-} tions at School, and Peer Acceptance. Spearman's correlations were used to analyze associations (1) between both mothers' and fathers' interactions and children's being prosocial, not overtly aggressive, and not being isolate in peer groups, (2) between peer acceptance and parents' interactive styles, and (3) between children's behaviors and peer acceptance.

(1) Some aspects of parents' interactive style, such as mothers' negative behavior and disconfirming and fathers' controlling, were associated with low prosociality $(r=.26 P<.05 ; r=.26 P<.05 ; r=$ $.31 P<.05$, resp.). Aggression was associated with both parents' disconfirming $(\mathrm{M} r=.23 \mathrm{P}<.07$; F $r=.30 P<.05)$.

(2) Being rejected in the peer group was associated with mothers' low positive behavior $(r=.35 P<.05)$ and with their being highly disconfirming $(r=.38 \mathrm{P}<$ .01 ), with both parents' negative behavior ( $\mathrm{Mr} r=$ $.33 P<.05 ; \mathrm{F} r=.33 P<.05)$ and still with fathers' control patterns $(r=.31 P<.05)$ Popularity correlated negatively with mothers' negative behavior $(r=-.37 P<.05)$, with both parents' control patterns $(\mathrm{M} r=-.33 \mathrm{P}<.05 ; \mathrm{F} r=-.28 \mathrm{P}<$ $.05)$ and still negatively with fathers' correcting $(r=$ $-.28 P<.05)$. Being average associated negatively with control patterns displayed by mothers and with both mothers' and fathers' disconfirming.

(3) Children's popularity was associated with high prosociality $(r=.33 P<.05)$, with low aggression $(r=$ $-.40 P<.05)$, which in turn correlated positively with rejection $(r=.37 P<.05)$; average correlated negatively with isolation $(r=-.51 P<001)$. 
TABle 1: Mean, mean rank, and Mann-Whitney $U$ of mothers' and fathers' interactive categories as function of their attachment classifications.

\begin{tabular}{|c|c|c|c|c|c|c|}
\hline \multirow{2}{*}{$\begin{array}{l}\text { Parental } \\
\quad \text { interactive styles }\end{array}$} & \multicolumn{2}{|c|}{ Secure } & \multicolumn{2}{|c|}{ Insecure } & \multicolumn{2}{|c|}{ Mann-Whitney } \\
\hline & Mean & Mean rank & Mean & Mean rank & $U$ & $P$ \\
\hline \multicolumn{7}{|l|}{ Positive behavior } \\
\hline Mothers & 14.24 & 22.31 & 6.00 & 12.09 & 57.50 & .003 \\
\hline Fathers & 13.38 & 21.53 & 5.41 & 12.74 & 63.50 & .009 \\
\hline \multicolumn{7}{|l|}{ Negative behavior } \\
\hline Mothers & 0.72 & 14.17 & 3.25 & 21.25 & 84.00 & .031 \\
\hline Fathers & 0.19 & 13.53 & 1.24 & 20.26 & 80.50 & .020 \\
\hline \multicolumn{7}{|l|}{ Control patterns } \\
\hline Mothers & 1.39 & 14.08 & 3.94 & 21.34 & 82.50 & .030 \\
\hline Fathers & 1.94 & 17.38 & 2.00 & 16.25 & 130.00 & .823 \\
\hline \multicolumn{7}{|l|}{ Neutral conversation } \\
\hline Mothers & 14.22 & 19.06 & 11.94 & 15.75 & 116.00 & .333 \\
\hline Fathers & 12.81 & 14.97 & 15.00 & 18.91 & 103.50 & .241 \\
\hline \multicolumn{7}{|l|}{ Correcting } \\
\hline Mothers & 2.78 & 18.58 & 2.19 & 16.28 & 124.50 & .490 \\
\hline Fathers & 1.31 & 16.41 & 1.29 & 17.56 & 126.50 & .707 \\
\hline \multicolumn{7}{|l|}{ Disconfirming } \\
\hline Mothers & 0.17 & 14.83 & 1.00 & 20.50 & 96.00 & .039 \\
\hline Fathers & 0.50 & 13.56 & 1.12 & 20.24 & 81.00 & .028 \\
\hline
\end{tabular}

Note: significant differences in bold.

TABLe 2: Differences (Mann-Whitney $U$ ) between children's behavioral orientation towards peers according to security and insecurity of their parents.

\begin{tabular}{|c|c|c|c|c|c|c|}
\hline \multirow{2}{*}{$\begin{array}{r}\text { Attachment } \\
\text { categories }\end{array}$} & \multicolumn{2}{|c|}{ Prosociality } & \multicolumn{2}{|c|}{ Aggression } & \multicolumn{2}{|c|}{ Isolation } \\
\hline & Mean rank & $U$ & Mean rank & $U$ & Mean rank & $U$ \\
\hline \multicolumn{7}{|l|}{ Mothers } \\
\hline Insecure & 13.81 & \multirow{2}{*}{$85.0^{*}$} & 19.38 & \multirow{2}{*}{114.0} & 19.16 & \multirow{2}{*}{117.5} \\
\hline Secure & 20.78 & & 15.83 & & 16.03 & \\
\hline \multicolumn{7}{|l|}{ Fathers } \\
\hline Insecure & 15.29 & 107.0 & 17.68 & 124.5 & 20.53 & $76.0^{*}$ \\
\hline Secure & 18.81 & & 16.28 & & 13.25 & \\
\hline
\end{tabular}

Note: ${ }^{*} P<.05$.

3.6. Parental Interactive Styles, Their Attachment Status, and Children's Behavioral Orientations at School: Their Discriminant Role as Far as Children's Popularity, Rejection, and Being Average in the Peer Groups Are Concerned. We then computed a logistic regression analysis in order to test the different role of parental interactive styles, their attachment status, and children's behavioral orientations at school as far as children's popularity, rejection, and being average in the peer groups are concerned (Table 3 ).

When the relationships with the mother were considered, we found that popularity was influenced primarily by children's behavior at school such as not being aggressive and secondly by a smaller frequency of mothers' control patterns. By contrast, rejection was related to mothers' being disconfirming and directly to their being insecure in their attachment. Being average at school was influenced mostly by children's not being isolated in the peer group.
When the father-child relationship was considered, we found popularity being affected mainly by fathers being less controlling and then, similarly to what emerges when relationships with mothers were considered, by children's not being aggressive; by contrast, rejection was affected by fathers' insecurity in their attachment; being average was affected by children's not being isolate at school.

3.7. Multidimensional Scaling Analysis (MDS) of Parents' Internal Working Models, Their Interactive Style, and Children's Peer Status in the Peer Group: Similarity Structure Analysis and External Variables as Points Technique Results. In this section we present results concerning the complex relation between parental interactive styles, their attachment working models, and children's peer status. Investigating this association implies establishing not only the terms in which IWM and children's peer acceptance relate to differences in 
TABLE 3: Logistic regressions (forward stepwise) considering the three children's peer status as dependent variables (DV; both for maternal and paternal interactive styles) having as independent variables the parental interactive categories (positive behaviour, negative behaviour, control patterns, neutral conversation, correcting, and disconfirming), the three children's behavioural orientations at school (prosocial, aggression and isolation), and the parent attachment internal working model (secure versus insecure).

\begin{tabular}{|c|c|c|c|c|c|c|c|c|}
\hline \multirow[t]{2}{*}{ Steps in the equation for each DV } & \multirow[t]{2}{*}{$B$} & \multirow{2}{*}{$\begin{array}{c}\text { Improvement } \\
\chi^{2}\end{array}$} & \multicolumn{5}{|c|}{ Model } & \multirow{2}{*}{$\begin{array}{c}\text { Nagel-kerke } \\
R^{2} \\
\end{array}$} \\
\hline & & & $\mathrm{df}$ & $P$ & $\chi^{2}$ & df & $P$ & \\
\hline \multicolumn{9}{|l|}{ Maternal iteractive styles } \\
\hline \multicolumn{9}{|l|}{ DV popular } \\
\hline (1) Aggression & -.308 & 6.043 & 1 & .014 & 6.043 & 1 & .014 & .218 \\
\hline (2) Control Patterns & -1.101 & 5.133 & 1 & .023 & 11.176 & 2 & .004 & .375 \\
\hline \multicolumn{9}{|l|}{ DV rejected } \\
\hline (1) Disconfirming & 1.74 & 8.734 & 1 & .003 & 8.734 & 1 & .003 & .341 \\
\hline (2) Secure & -2.43 & 5.059 & 1 & .024 & 13.793 & 2 & .001 & .502 \\
\hline \multicolumn{9}{|l|}{ DV average } \\
\hline (1) Isolation & -1.472 & 9.994 & 1 & .002 & 9.994 & 1 & .002 & .356 \\
\hline \multicolumn{9}{|l|}{ Paternal interactive styles } \\
\hline \multicolumn{9}{|l|}{ DV popular } \\
\hline (1) Control patterns & -.514 & 7.925 & 1 & .005 & 7.925 & 1 & .005 & .285 \\
\hline (2) Aggression & -.872 & 4.100 & 1 & .043 & 12.025 & 2 & .002 & .408 \\
\hline \multicolumn{9}{|l|}{ DV rejected } \\
\hline (1) Secure & -2.351 & 6.039 & 1 & .014 & 6.039 & 1 & .014 & .250 \\
\hline \multicolumn{9}{|l|}{ DV average } \\
\hline (1) Isolation & -1.407 & 9.036 & 1 & .003 & 9.036 & 1 & .003 & .339 \\
\hline
\end{tabular}

parents' behavioral categories but also describing the global structure of the latter and relating this structure to the other two groups of variables. For this analysis we relied on a multidimensional scaling approach (MDS) using "similarity structure analysis (SSA)" and the "external variables as points technique" developed by Cohen and Amar [58-60].

These techniques provide a more appropriate way of computing this complex relationship than traditional statistical methods and represent something new in this area of investigation. Indeed, in the preceding analyses reported above, conducted using well-known tests, it was not possible to explore the interrelation of all the variables simultaneously (the structure of parental categories, children's social status, and parents' attachment). By contrast the SSA tests allow a similarity structure plot to be created which represents the intercorrelations between the parental behavioral categories (content variables), and then to introduce external variables such as parents' IWM and children's acceptance in terms of points in the MDS maps. More specifically, SSA allows variables to be displayed as points in a Euclidean space denoted as "smallest space." The intercorrelations, which are used such as an empirical measure of similarity among variables, are represented in that space by distances between pairs of points. Rather than using a least square transformation, SSA sorts the distances into the order specified by the data [57]. By inserting external variables and by locating them in the SSA space it is possible to obtain more detailed information about population subgroups.

Among the MDS, the SSA (smallest space analysis- [7376] or similar structure analysis-[77]) was used in so far as it is a more suitable nonparametric multidimensional scaling procedure for small samples such as ours. Furthermore, this method has proved useful in dealing with data obtained from observational studies, specifically microanalytical observation of parent-child interaction [78].

Questions were what is the structure of parental behavioral categories underlying a child's relationship with his/her mother and father? and how does this structure relate both to parents' attachment and peer social status?

We were expecting that the twelve behavioral categories (six for mothers and six for fathers) were istributed according to a polar structure and that they could be graphically represented in a circular diagram. The MDS analysis supports our hypothesis.

Figure 1 presents the SSA plot of the six mothers' and fathers' interactions with children's social status and parents' IWM as external variables. The coefficient of alienation is 0.09 , indicating a good fit between the SSA solutions and the input correlation matrices. In fact the coefficient of alienation is an index of the goodness of fit between original data and the SSA solutions. Its range is between 1 and 0.0 indicates a perfect fit. A value under 2 indicates a good fit.

In order to interpret the result of this analysis more fully we report also the MU (week monotonicity coefficient) of the variables included in the equation.

In each region same content categories for each parent are fairly close to one another with the exception of neutral conversation and negative Behaviors. On the right side of the plot we observe two categories which seem to characterize a "responsive style," positive behavior (PB) at the top and neutral conversation (NC) at the bottom. Nevertheless, their location indicates the different roles they 


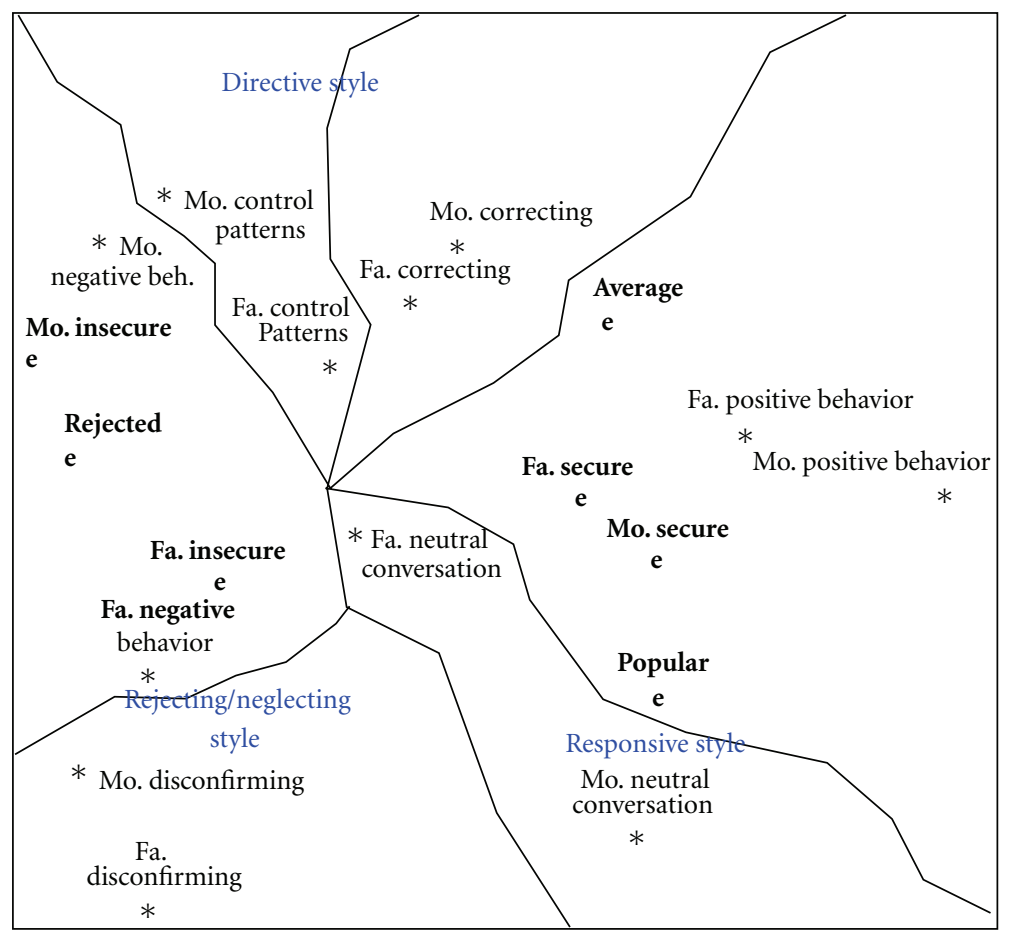

FIGURE 1: SSA projection of the mothers' (Mo.) and fathers' (Fa.) behavioral categories (positive behavior, negative behavior, control patterns, neutral conversation, correcting, and disconfirming) with children's peer social status (e: popular, average and rejected) and parents' attachment Internal Working Model (e: secure and unsecure) as external variables (dimensions $1 \times 2$ of the 3-D, coefficient of alienation .09).

play in the parent-child interaction: while the first one (PB) signals an obvious positive style of the parent, the second one (NC) merely indicates his/her availability to deal with the child and to interact with him/her. The relationship between these behavioral categories is negative (stronger for fathers $(\mathrm{PB} / \mathrm{NC}-.83)$ than for mothers $(-.32))$. Thus, it is interesting to underline that parents who were highly positive to their children, that is who spent time interacting with, helping, and encouraging them, were less keen to simply engage in a conversation on neutral themes.

On the left side of the plot from the bottom and moving clockwise we observe two behavioral categories that actually share a clearly devaluating attitude towards the child as a person, disconfirming (DS) and negative behaviors (NB). This type of behavior could be viewed as characterizing a "rejecting/neglecting style." Moving further clockwise we found two parental behavioral categories, correcting (CO) and control patterns (CP), which characterized a sort of "directive style" of interaction.

Correcting is located in a region between control patterns on the left side and positive behavior on the right. Correcting indeed plays a triggering role in the main stream of parental interactive style in so far as both the gentle teaching of skills a child does not yet have and keeping his/her attention on the errors the child makes are coded in this category.

As far as the location of peer acceptance is concerned, while the external variable indicating an average social status is found between correcting and positive behavior, the other external variable indicating popularity of children is located between neutral conversation and positive behavior. Not surprisingly, quite close to positive behavior we observe also the security of mothers' and fathers' external variables indicating quite a high correlation between attachment and PB (for mothers' IWM the correlation with positive behaviors is .79 , for fathers it is .73).

The correlations between the other behavioral categories and popularity are negative and quite high especially as far as Controlling ( -.67 mothers, -.81 fathers) is concerned; also negative behavior is quite high, but only for mothers $(-.78)$ (for fathers-.11).

It is also not surprising that an external variable such as children's rejection is located in the same region (left side of the plot opposite to positive behaviors). Rejection correlates quite negatively with $\mathrm{PB}(-.85$ mothers, -.78 fathers), and positively with all the other categories-with the exception of the neutral conversations for mothers (.50) (for mothers: Co.17; CP.18; DS.71 and NB.64. For fathers: NC.27, CO.14, CP.59, DS.39, and NB.67). Furthermore, quite close to rejection we found mothers' and fathers' insecure attachments (at top and bottom, resp.). While mothers insecure IWM showed strong positive correlation with control patterns (.71), disconfirming (.82), and negative behavior (.83) and negative correlation with the other three behavioral categories (especially $\mathrm{PB}-.79$ ), fathers' insecure IWM showed a strong positive correlation with disconfirming (.52) and negative behavior (.86) and a strong negative correlation only with positive behavior $(-.73)$. 


\section{Discussion and Concluding Remarks}

Our results provide further evidence of the strong associations between parents' mental organization of attachment and the quality of their relationships with their children, as already found in previous studies [23-28]. Nevertheless, to our knowledge, this is the first study to show connections between parents' IWM and the several aspects of their everyday life rearing interactions. In detail, we found that attachment security in both mothers and fathers was linked to a relationship based on more positive behaviors-such as comforting, encouraging, helping, and protecting - and on less negative behaviors-such as criticizing, threatening, interfering, and being hostile-and disconfirming patterns - such as ignoring and answering irrelevantlythan it was the case when the associations with parents' attachment insecure internal working models were considered. Furthermore, secure mothers were less controlling than insecure ones (numbers did not reach statistical significance for fathers). Indeed these results are in line with data by Adam and colleagues [25] who found in dismissing mothers' lower levels of positive affectivity and in entangled ones higher levels of negative affectivity and anxiety combined with angry/intrusive parenting.

It is also significant to consider the associations between parents' IWM and children's social competence, given that the latter might be assumed to be an element of a child's internal working model; for this reason our results might be considered to provide further evidence of the intergenerational transmission of attachment. Indeed, we found that insecure mothers' and fathers' attachment status entailed risk factors not only for a problematic parentchild relationship but also for children's displaying social competence in peer groups. Insecure parents had children who were less prosocial, more isolate, and who tended to be more aggressive at school. Furthermore, popular and average children in the peer group had a higher percentage of secure mothers and fathers while the reverse was true for the rejected ones.

Our results show also, in line with the model devised by Michiels et al. [56] who stress the link between parentchild interactions and relational aggression in peer groups, that children's lack of social competence correlates with several aspects of parents' interactive styles and mainly with parenting items such as negative and disconfirming interactions and a lack of positive behaviour, which themselves were linked to adults' IWM. Cowan and colleagues [24] have even found that insecure adult attachment predict later adaptation: their insecure mothers displayed low level of authoritative parenting which in turn was associated with children's high levels of internalizing and externalizing behavior one year later at school. Thus it is possible to argue that the quality of mother-child and father-child relationships might be an operative factor linking parents' mental representations of attachment and children's adaptation in peer groups. Indeed we also found, in line with a large body of previous studies on this topic starting with Coie et al. [51], that children who were more prosocial were also more popular, and that those who were more aggressive were less popular and more rejected; those who were not withdrawing from others were at least average. For this reason children's behavior might be considered a mechanism by which parental styles and social success are related.

These results are in line with research arguing and demonstrating that subsequent parents' sensitivity has a great role, with espect to early attachments, in children's adjustment ([5, 35-38]; for a review, see [7]).

In other words, according to what Laible [18] found for adolescence, our findings suggest that relationships with secure parents foster social behavior which leads to being popular among peers by promoting high levels of positive interactions and low levels of negative dominant expressiveness. Children who were involved in relationships with their parents characterized by positive behaviors such as encouragement and helping were better able to develop the skills necessary for initiating and maintaining warm relationships with peers.

The previous findings are in line with what we found with the regression analysis aimed to consider the discriminant role of parents' interactive styles, their attachment status, and children's behavioral orientations in popularity, rejection, and being average in peer groups. Children's behavior at school did have a major effect on popularity rather than aspects of mothers' interactive styles (not to be aggressive is more effective than a lack of directiveness by the mother in predicting popularity). Nevertheless, by contrast, rejection was predicted by mothers' disconfirming at home and by both parents insecurity in their attachment.

Last, the integrated analysis of similarity structure (SSA) and external variables, based on a statistical method that represents an innovation in this area of investigation, allowed us to better comprehend this complex link and the extent to which the quality of the parent-child relationship and their attachment status relate to children's social status.

As far as the structure underlying parental behavioral categories is concerned, the circular order of these categories indicates that this facet, whose elements represent unordered qualitative aspects of a content universe, plays a polar role by partitioning the SSA space into wedge-shaped regions. Some behavioral categories were closer to one another according to whether their content defines different interactive modalities which appear, in regards to their content, in line with Baumrind $[67,68]$ conceptualization of parenting styles. In other words, adjacent regions corresponded to elements of facets that were conceptually more similar; thus, negative behavior and disconfirming could be seen as characterizing a "rejecting/neglecting style" while two parental behavioral categories such as positive behavior and neutral conversation seem to characterize a "responsive style"; by contrast correcting and control patterns appear to characterize a sort of "directive style" of interaction.

These analyses also evidenced the complex link between parents' attachments and their interactive style. Interestingly, mothers and fathers IWM were located close to each other. Indeed, in agreement with the meta-analyses by Van Ijzendoorn and Bakermans-Kranenburg [79] we found strong associations between the AAI classifications of wives and husbands; this result gives the picture of children being 
exposed to a double risk when both parents were insecure in their attachments. Not surprisingly secure IWM appear to be close to a "responsive style" (in line with what we know from the attachment theory) while insecure ones are close to rejecting/neglecting and directive styles. Nevertheless we also need to stress, in line with results by Cowan et al. [24], that mothers' attachment plays a more direct and stronger role within the structure of parental behavioral categories than fathers'. Indeed, the distance between security and insecurity in the case of the fathers is smaller compared to that found for mothers.

As far as the link between parents' interactive style and children's peer status at school is concerned, rejection appears to be linked to parents' behaviors expressing a devaluating attitude towards them; by contrast, popularity appears close to behavior categories mediating their parents' positive and responsive attitudes towards them; average is located in a region intermediate between positive behavior by both parents and a directive style (correcting and control patterns) indicating that a child who does not receive only controls but also warmth and supportiveness can at least become average.

In conclusion, we do not know anything about the antecedent attachment experiences these children had in their infancy; nevertheless, we can say, in line with what is suggested and/or proved by Belsky and Fearon [35], Lamb et al. [37], and Lewis et al. [38] that concurrent relationships with parents shape children's behavioral development. Furthermore, in line with what has been already found by Adam et al. [25], Cohn et al. [23], Cowan et al. [24], Crowell et al. [28], Crandell et al. [26], Crowell and Feldman [27], our data show that mothers' and fathers' actual attachment mental states greatly affect their interactive styles. Thus, even though in our study there is no way to test competing alternative hypotheses about what other family (such as, for example the couple attachment, as found by Cowan et al. [24]) and peer mechanisms might intervene in the connection between parents' attachment mental organizations and children's peer acceptance, our results allow us to argue in favour of the hypothesis that the quality of family relationships can be viewed as a primary mechanism by which the transmission of attachment can occur in order to give children the possibility of acquiring social competence in the peer groups.

There are several limits to our study: small sample size, which means that results are difficult to generalize; nevertheless, they are in line with what is expected within the attachment theory, and with the literature on this topic, and are based on nonparametric statistics. Another limit is the use, in some analyses, of correlational tests, which means that it is difficult to detect the direction of the causes and effects: children's behavioral orientations at school, for example, might be both the result of parents' rearing styles and their "cause" in the case they revealed a personal characteristic of the child. The lack of a longitudinal perspective which might give some idea of the long-term effects of the link between parents' IWM and parent-child relationships is another limit.

Future research should focus in greater detail on mechanisms working in the transmission of attachment across generations and should provide some insight into the possibility of a bidirectional influence of peer and family relationships on children's social competence. Furthermore, it might be worth validating our findings in different cultural and social settings.

\section{References}

[1] J. Bowlby, Attachment and Loss: Vol. 1 Attachment, Basic Books, New York, NY, USA, 1969.

[2] J. Bowlby, Attachment and Loss: Vol. 2 Separation, Basic Books, New York, NY, USA, 1973.

[3] K. Lyons-Ruth, "Attachment relationships among children with aggressive behavior problems: the role of disorganized early attachment patterns," Journal of Consulting and Clinical Psychology, vol. 64, no. 1, pp. 64-73, 1996.

[4] K. McCartney, M. T. Owen, C. L. Booth, A. Clarke-Stewart, and D. L. Vandell, "Testing a maternal attachment model of behavior problems in early childhood," Journal of Child Psychology and Psychiatry and Allied Disciplines, vol. 45, no. 4, pp. 765-778, 2004.

[5] N. L. McElwain, M. J. Cox, M. R. Burchinal, and J. Macfie, "Differentiating among insecure mother-infant attachment classifications: a focus on child-friend interaction and exploration during solitary play at 36 months," Attachment and Human Development, vol. 5, no. 2, pp. 136-164, 2003.

[6] J. A. Munson, R. J. McMahon, and S. J. Spieker, "Structure and variability in the developmental trajectory of children's externalizing problems: impact of infant attachment, maternal depressive symptomatology, and child sex," Development and Psychopathology, vol. 13, no. 2, pp. 277-296, 2001.

[7] B. H. Schneider, L. Atkinson, and C. Tardif, "Child-parent attachment and children's peer relations: a quantitative review," Developmental Psychology, vol. 37, no. 1, pp. 86-100, 2001.

[8] D. S. Shaw and J. I. Vondra, "Infant attachment security and maternal predictors of early behavior problems: a longitudinal study of low-income families," Journal of Abnormal Child Psychology, vol. 23, no. 3, pp. 335-357, 1995.

[9] L. A. Sroufe, "Attachment classification from the perspective of infant-caregiver relationships and infant temperament," Child Development, vol. 56, no. 1, pp. 1-14, 1985.

[10] R. A. Thompson, "Early sociopersonality development," in Handbook of Child Psycholog, W. Damon, Ed., vol. 3 of $[x]$ Social, Emotional, and Personality Development, pp. 25-104, John Wiley \& Sons, New York, NY, USA, 1998.

[11] M. H. Van Ijzendoorn, "Attachment, emergent morality, and aggression: toward a developmental socioemotional model of antisocial behaviour," International Journal of Behavioral Development, vol. 21, no. 4, pp. 703-727, 1997.

[12] G. Bohlin, B. Hagekull, and A. M. Rydell, "Attachment and social functioning: a longitudinal study from infancy to middle childhood," Social Development, vol. 9, no. 1, pp. 2439, 2000.

[13] D. H. Dallaire and M. Weinraub, "Infant-mother attachment security and children's anxiety and aggression at first grade," Journal of Applied Developmental Psychology, vol. 28, no. 5-6, pp. 477-492, 2007.

[14] D. Granot and O. Mayseless, "Attachment security and adjustment to school in middle childhood," International Journal of Behavioral Development, vol. 25, no. 6, pp. 530-541, 2001.

[15] T. Jacobsen and V. Hofmann, "Children's attachment representations: longitudinal relations to school behavior and academic competency in middle childhood and adolescence," Developmental psychology, vol. 33, no. 4, pp. 703-710, 1997. 
[16] J. Urban, E. Carlson, B. Egeland, and L. A. Sroufe, "Patterns of individual adaptation across childhood," Development and Psychopathology, vol. 3, pp. 445-460, 1991.

[17] R. C. M. E. Engels, C. Finkenauer, W. Meeus, and M. Deković, "Parental attachment and adolescents' emotional adjustment: the associations with social skills and relational competence," Journal of Counseling Psychology, vol. 48, no. 4, pp. 428-439, 2001.

[18] D. Laible, "Attachment with parents and peers in late adolescence: links with emotional competence and social behavior," Personality and Individual Differences, vol. 43, no. 5, pp. 11851197, 2007.

[19] K. G. Rice, "Attachment in adolescence: a narrative and metaanalytic review," Journal of Youth and Adolescence, vol. 19, no. 5, pp. 511-538, 1990.

[20] K. J. Simons, C. E. Paternite, and C. Shore, "Quality of parent/ adolescent attachment and aggression in young adolescents," Journal of Early Adolescence, vol. 21, no. 2, pp. 182-203, 2001.

[21] D. Cicchetti and M. T. Greenberg, "Special issue: attachment and developmental psychopathology," Development and Psycholopathology, vol. 3, no. 4, 1991.

[22] J. Belsky and E. Pensky, "Developmental history, personality and family relationships: toward an x emergent family system," in Relationships within Families: Mutual Inlfuences, R. Hinde and J. Stevenson-Hinde, Eds., pp. 193-217, Clarendon Press, Oxford, UK, 1988.

[23] D. A. Cohn, P. A. Cowan, C. P. Cowan, and J. Pearson, "Mothers' and fathers' working models of childhood attachment relationships. Parenting styles, and child behaviour," Development and Psychopathology, vol. 4, pp. 417-431, 1992.

[24] P. A. Cowan, C. P. Cowan, and N. Mehta, "Adult attachment, couple attachment, and children's adaptation to school: an integrated attachment template and family risk model," Attachment and Human Development, vol. 11, no. 1, pp. 2946, 2009.

[25] E. K. Adam, M. R. Gunnar, and A. Tanaka, "Adult attachment, parent emotion, and observed parenting behavior: mediator and moderator models," Child Development, vol. 75, no. 1, pp. 110-122, 2004.

[26] L. E. Crandell, H. E. Fitzgerald, and E. E. Whipple, "Dyadic synchrony in parent-child interactions: a link with maternal representations of attachment relationships," Infant Mental Health Journal, vol. 18, no. 3, pp. 247-264, 1997.

[27] J. A. Crowell and S. S. Feldman, "Mothers' internal models of relationships and children's behavioral and developmental status: a study of mother-child interaction," Child Development, vol. 59, no. 5, pp. 1273-1285, 1988.

[28] J. A. Crowell, E. O’Connor, G. Wollmers, J. Spreakin, and U. Rao, "Mothers' conceptualisations of parent-child relationships: relation to mother-child interaction and child behavior problems," Development \& Psychopathology, vol. 3, pp. 431444, 1991.

[29] M. Main and R. Goldwin, "Interview based adult attachment classification: related to infant-mother and infant-father attachment," Developmental Psychology, pp. 223-233, 1991.

[30] M. H. Van Ijzendoorn, "Adult attachment representations, parental responsiveness, and infant attachment: a metaanalysis on the predictive validity of the adult attachment interview," Psychological Bulletin, vol. 117, no. 3, pp. 387-403, 1995.

[31] E. Hesse, " $x$ Adult attachment interview: historical and current perspectives," in Handbook of Attachment: Theory, Research, and Clinical Applications, J. Cassidy and P. R. Shaver, Eds., pp. 395-433, The Guilford Press, New York, NY, USA, 1999.
[32] M. D. S. Ainsworth, M. C. Blehar, E. Waters, and S. Wall, Patterns of Attachment: A Psychological Study of the Strange Situation, Erlbaum, Hillsdale, NJ, USA, 1979.

[33] M. K. Freitag, J. Belsky, K. Grossmann, K. E. Grossmann, and H. Scheuerer-Englisch, "Continuity in parent-child relationships from infancy to middle childhood and relations with friendship competence," Child Development, vol. 67, no. 4, pp. 1437-1454, 1996.

[34] L. M. Youngblade, K. A. Park, and J. Belsky, "Measurement of young children's close friendship: a comparison of two independent assessment systems and their associations with attachment security," International Journal of Behavioral Development, vol. 16, pp. 563-587, 1993.

[35] J. Belsky and R. M. P. Fearon, "Early attachment security, subsequent maternal sensitivity, and later child development: does continuity in development depend upon continuity of caregiving?" Attachment and Human Development, vol. 4, no. 3, pp. 361-387, 2002.

[36] M. E. Lamb, "Predictive implications of individual differences in attachment," Journal of Consulting and Clinical Psychology, vol. 55, no. 6, pp. 817-824, 1987.

[37] M. E. Lamb, R. Thompson, W. Gardner, and E. Charnov, Infant-Mother Attachment: The Origins and Developmental Significance of Individual Differences in Strange Situation Behavior, Erlbaum, Hillsdale, NJ, USA, 1985.

[38] M. Lewis, C. Feiring, and S. Rosenthal, "Attachment over time," Child Development, vol. 71, no. 3, pp. 707-720, 2000.

[39] J. Grusec and H. Lytton, Social Development, Springer, New York, NY, USA, 1988.

[40] G. W. Ladd, "Peer relationships and social competence during early and middle childhood," Annual Review of Psychology, vol. 50, pp. 333-359, 1999.

[41] J. Belsky and J. Cassidy, "Attachment: theory and evidence," in Development Through Life: A Handbook for Clinicians, M. Rutter and D. Hay, Eds., pp. 373-402, Blackwell Scientific Publications, Oxford, UK, 1994.

[42] S. R. Asher and J. Coie, Peer Rejection in Childhood, Cambridge University Press, New York, NY, USA, 1990.

[43] C. Howes and L. Phillipsen, "Continuity in children's relations with peers," Social Development, vol. 7, no. 3, pp. 340-349, 1998.

[44] K. H. Rubin, "The Waterloo Longitudinal Project: continuities of social withdrawal from early childhood to early adolescence," in Social Withdrawal, Inhibition, and Shyness in Childhood, K. H. Rubin and J. Asendorpf, Eds., Erlbaum, Hillsdale, NJ, USA, 1993.

[45] M. L. Diener and D. O. Y. Kim, "Maternal and child predictors of preschool children's social competence," Journal of Applied Developmental Psychology, vol. 25, no. 1, pp. 3-24, 2004.

[46] W. W. Hartup, "Peer relations," in Handbook of Child Psychology, P. H. Mussen and E. M. Hetherington, Eds., vol. 4 of Socialization, Personality and Social Development, pp. 103-196, John Wiley \& Sons, New York, NY, USA, 1983.

[47] G. Attili, "Successful and disconfirmed children in the peer group: indices of social competence within an evolutionary perspective," Human Development, vol. 33, pp. 238-249, 1990.

[48] A. S. Masten and J. D. Coatsworth, "The development of competence in favorable and unfavorable environments," American Psychologist, vol. 53, no. 2, pp. 205-220, 1998.

[49] L. Rose-Krasnor, "The nature of social competence: a theoretical review," Social Development, vol. 6, no. 1, pp. 110-135, 1997.

[50] G. Attili, P. Vermigli, and B. H. Schneider, "Peer acceptance and friendship patterns among Italian schoolchildren within a 
cross-cultural perspective," International Journal of Behavioral Development, vol. 21, no. 2, pp. 277-288, 1997.

[51] J. D. Coie, K. A. Dodge, and J. B. Kupersmith, "Dimensions and types of social status," in Peer Rejection in Childhood, S. R. Asher and J. D. Coie, Eds., pp. 17-59, Cambridge University Press, New York, NY, USA, 1990.

[52] K. A. Dodge, J. D. Coie, G. S. Pettit, and J. M. Price, "Peer status and aggression in boys' groups: developmental and contextual analyses," Child Development, vol. 61, no. 5, pp. 1289-1309, 1990.

[53] R. J. Coplan, K. H. Rubin, N. A. Fox, S. D. Calkins, and S. L. Stewart, "Being alone, playing alone, and acting alone: distinguishing among reticence and passive and active solitude in young children," Child Development, vol. 65, no. 1, pp. 129 137, 1994.

[54] K. H. Rubin, W. Bukowski, and J. G. Parker, "Peer interactions, relationships, and groups," in Handbook of Child Psychology, W. Damon, Ed., pp. 619-700, John Wiley \& Sons, New York, NY, USA, 1998.

[55] A. F. Newcomb, W. M. Bukowski, and L. Pattee, "Children's peer relations: a meta-analytic review of popular, rejected, neglected, controversial, and average sociometric status," Psychological Bulletin, vol. 113, no. 1, pp. 99-128, 1993.

[56] D. Michiels, H. Grietens, P. Onghena, and S. Kuppens, "Parent-child interactions and relational aggression in peer relationships," Developmental Review, vol. 28, no. 4, pp. 522540, 2008.

[57] L. Guttman, Coefficients of Polytonicity and Monotonicity. Encyclopedia of Statistical Sciences, vol. 7, John Wiley \& Sons, New York, NY, USA, 1986.

[58] E. H. Cohen and R. Amar, "External variables in SSA, including external profiles and POSAC regions," in Proceedings of the 4th International Facet Theory Conference, pp. 375-385, Prague, Czech Republic, 1993.

[59] E. H. Cohen and R. Amar, "External variables in SSA and unfolding techniques: a comparison," in Proceedings of the 7th International Facet Theory Conference, Design and Analysis, R. M. Sweitzer, Ed., pp. 259-279, Facet Theory Association, Berne, Switzerland, 1999.

[60] E. H. Cohen and R. Amar, "External variables as points in smallest space analysis: a theoretical, mathematical and computer-based contribution," Bulletin de Méthodologie Sociologique, vol. 75, pp. 40-56, 2002.

[61] C. George, N. Kaplan, and M. Main, The Adult Attachment Interview, University of California, Berkeley, Calif, USA, 1984.

[62] M. Main and R. Goldwin, Adult Attachment Scoring and Classification System, University of California, Berkeley, Calif, USA, 1984.

[63] R. A. Hinde and J. Stevenson-Hinde, "Interpersonal relationships and child development," Developmental Review, vol. 7, no. 1, pp. 1-21, 1987.

[64] R. A. Hinde and A. Tamplin, "Relations between motherchild interaction and behaviour in preschool," British Journal of Developmental Psychology, vol. 1, pp. 231-257, 1983.

[65] G. Attili, "Social competence versus emotional security: the link between home relationships and behaviour problems in preschool," in Social Competence in Developmental Perspective, B. H. Schneider, G. Attili, J. Nadel, and R. P. Weissberg, Eds., pp. 293-311, Kluwer Academic, Dodrecht, The Netherlands, 1989.

[66] R. A. Hinde, Unpublished Coding Manual, Harvard University Press, Cambridge, Mass, USA, 1983.
[67] D. Baumrind, "Child care practices anteceding three patterns of preschool behavior," Genetic Psychology Monographs, vol. 75, no. 1, pp. 43-88, 1967.

[68] D. Baumrind, "The influence of parenting style on adolescent competence and substance use," Journal of Early Adolescence, vol. 11, no. 1, pp. 58-95, 1991.

[69] R. A. Hinde, D. F. Easton, R. E. Meller, and A. M. Tamplin, "Temperamental characteristics of 3-4-year-olds and motherchild interaction," Ciba Foundation Symposium, vol. 89, pp. 66-86, 1982.

[70] J. D. Coie, K. A. Dodge, and H. Coppotelli, "Dimensions and types of social status: a cross-age perspective," Developmental Psychology, vol. 18, no. 4, pp. 557-570, 1982.

[71] J. D. Coie and K. A. Dodge, "Multiple sources of data on social behavior and social status in the school: a cross-age comparison," Child Development, vol. 59, no. 3, pp. 815-829, 1988.

[72] J. E. Ledingham and A. J. Younger, "The influence of the evaluator on assessment of chidren's social skills," in Children's Peer Relations: Issues in Assessment and Intervention, B. H. Scheider, K. H. Rubin, and J. E. Ledingham, Eds., pp. 111-121, Springer, New York, NY, USA, 1985.

[73] K. D. Bayley, "Interpreting smallest space analysis," Sociological Methods and Research, vol. 32, no. 3, pp. 3-29, 1974.

[74] M. Bloombaum, "Doing smallest space analysis," Journal of Conflict Resolution, vol. 14, no. 3, pp. 409-416, 1970.

[75] L. Guttman, "A general nonmetric technique for finding the smallest coordinate space for a configuration," Psychometrika, vol. 33, no. 4, pp. 469-506, 1965.

[76] S. Shye, Multiple Scaling, North-Holland, Amsterdam, The Netherlands, 1985.

[77] J. Borg and J. C. Lingoes, Multidimensional Similarity Structure Analysis, Springer, New York, NY, USA, 1987.

[78] M.S. Silva, M. C. D. P. Lyra, and A. Roazzi, "The development of mother-object-infant communication: methodological contributions from facet theory," in Facet Theory: Integrating Theory Construction with Data Analysis, D. Elizur, Ed., pp. 367-383, Matfyzpress, Prague Czech Republic, 2001.

[79] M. H. Van Ijzendoorn and M. J. Bakermans-Kranenburg, "Attachment representations in mothers, fathers, adolescents, and clinical groups: a meta-analytic search for normative data," Journal of Consulting and Clinical Psychology, vol. 64, no. 1, pp. 8-21, 1996. 


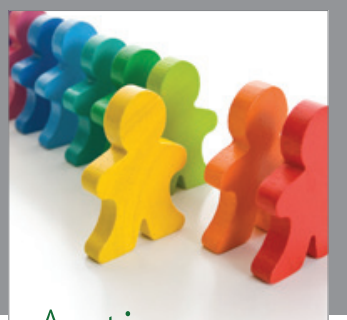

Autism

Research and Treatment
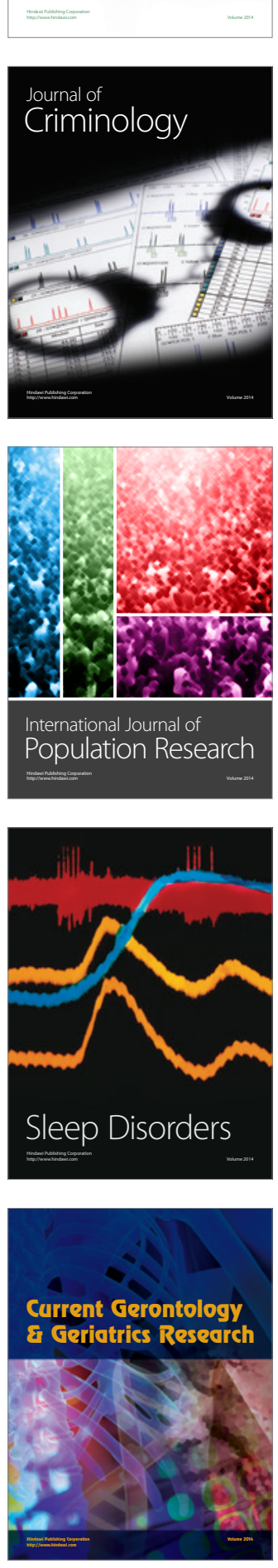
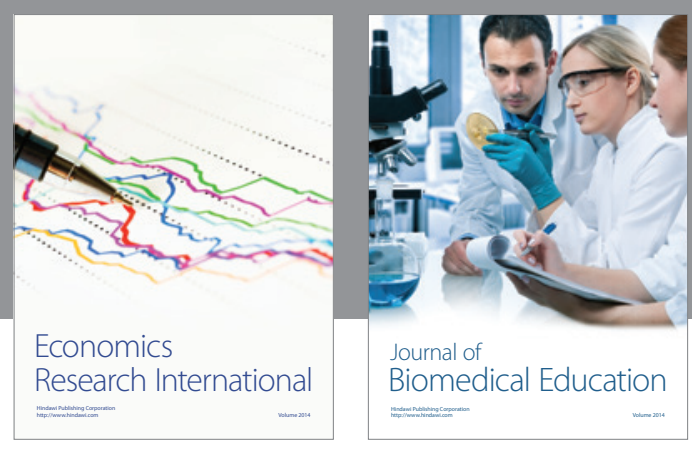

Journal of

Biomedical Education

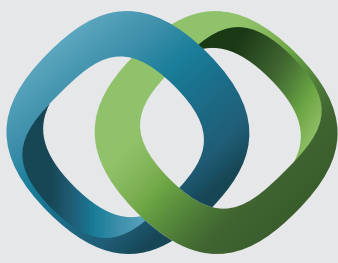

\section{Hindawi}

Submit your manuscripts at

http://www.hindawi.com
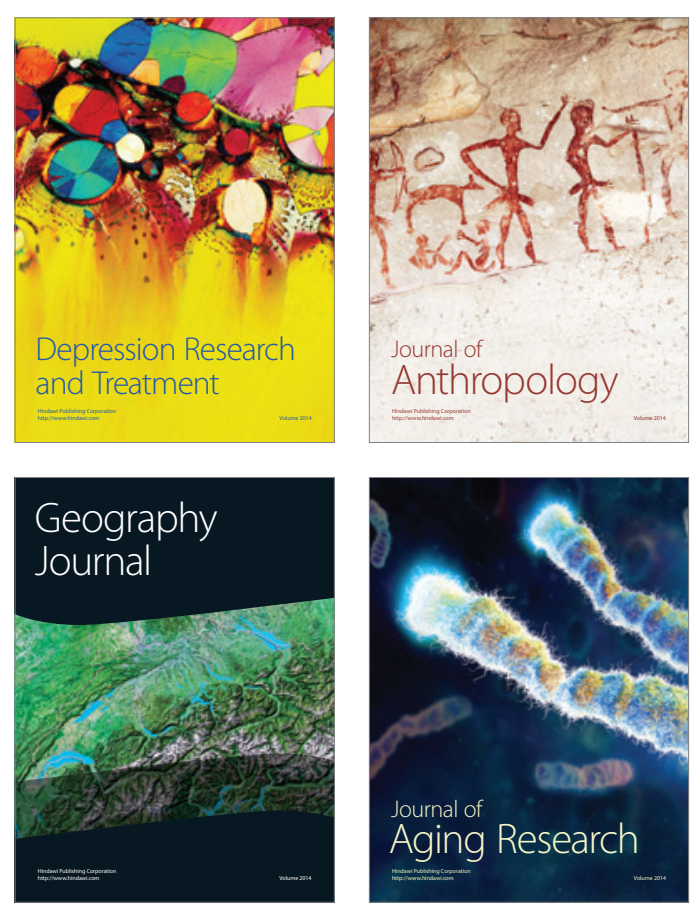

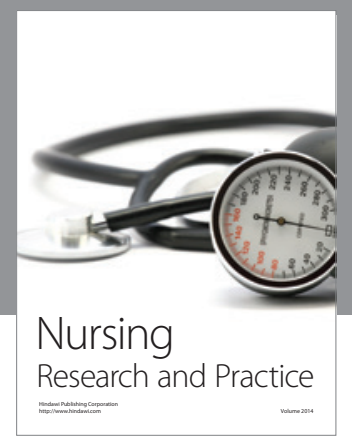

Nursing

Research and Practice

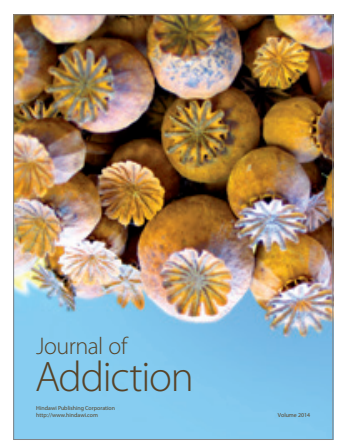

Child Development

Research

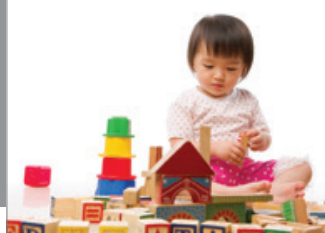

迥
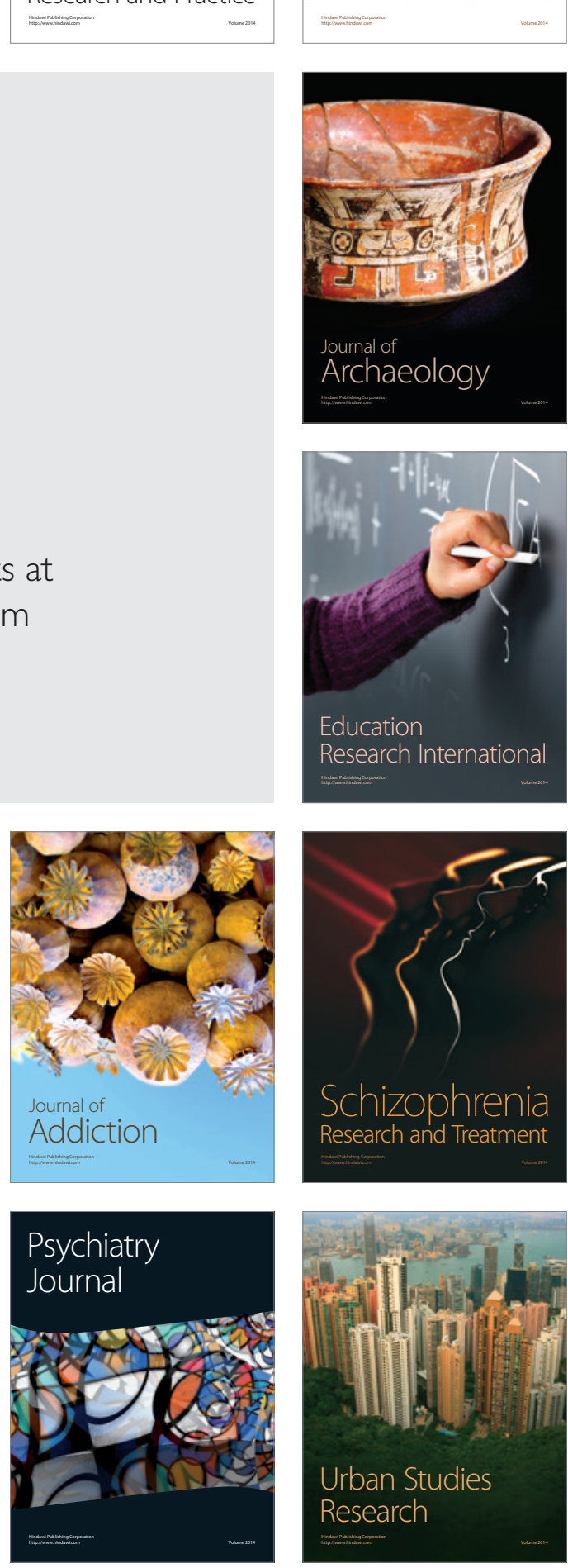